\title{
Measurement of indoor air quality under different heating modes in western Sichuan
}

\author{
Zou Hang ${ }^{1}$, Liu Zhanqiang ${ }^{2}$, Guo Xiaojuan ${ }^{3}$, and Long Enshen ${ }^{4, *}$ \\ ${ }^{1}$ China Construction First Group, 100071, Beijing, China \\ ${ }^{2}$ China Construction First Group, 100071, Beijing, China \\ ${ }^{3}$ China Construction First Group, 100071, Beijing, China \\ ${ }^{4}$ College of Architecture and Environment, Sichuan University, 610065, Chengdu, China
}

\begin{abstract}
Western Sichuan region has a variety of traditional heating methods and excellent outdoor air quality, and the difference with the city is clear. The indoor air quality of the western Sichuan region is worth studying. The diffusion law of indoor and outdoor PM2.5 concentration under different heating methods can be explored to provide effective data support for environmental governance. In this context, the indoor air quality under different heating methods in Songpan County was measured with PM2.5 concentration assessment of indoor air quality (IAQ). By analyzing the indoor air quality under different heating modes, the following conclusions can be drawn: the influence degree of indoor activity on indoor particle concentration level depends on the source and characteristics of the house. Air leakage is one of the main reasons for the rise of indoor PM2.5. Heating methods disturb the indoor air, which significantly affects the migration of PM2.5.
\end{abstract}

\section{Introduction}

Most people spend more than $85 \%$ of their time in a variety of indoor environments (home, school, office and restaurant), and particulate matter assessment of indoor air quality (IAQ) has become one of the important topics in air pollution research. Particulate matter is a widely found type of suspended particle that is large enough for a person to breathe. Particulate matter is usually a mixture of particles and droplets, representing a complex mixture of organic and inorganic matter. In the atmosphere, fine particulate matter (PM2.5) can move freely with air currents, stay suspended for days to weeks, and can travel hundreds to thousands of kilometers. PM2.5 can vary in shape, source, size and chemical composition and can include metals, soot, soil, water droplets and dust. Under indoor conditions, PM2.5 tends to settle slowly from indoor air, although it often adheres to any surface it touches.

Any household has many sources of indoor air pollution. These include sources of combustion, such as heating and cooking systems, oil, coal, wood and tobacco products; Building materials, such as spoiled asbestos insulation; Furniture, such as damp or damp carpets, certain types of pressed wood furniture; Household chemical products; Outdoor sources.

Many studies in different countries have investigated, identified and quantified indoor particulate matter in different building types, such as Wallace[1]. As for indoor particulate matter in residential buildings, different studies show different indoor PM2.5 levels. Haller et al. [2] reported an average concentration of $10.8 \mathrm{mg} / \mathrm{m}^{3}$ in the United States. Jones et al. [3] found a value of $7.9 \mathrm{mg} / \mathrm{m}^{3}$ in Birmingham, UK, showing the maximum PM2.5 concentration in winter [4]. Cao et al. [5] concluded that both indoor and outdoor PM2.5 levels showed an upward trend from rural, urban and roadside environments. Using expiratory reserve, Green and Morris [6] showed that PM2.5 concentrations in summer and autumn increased the risk of childhood asthma by $4.3 \%$ and $2.1 \%$, respectively. Chunram et al. [7] found that in the urban area of Chiang Mai, the monthly average indoor PM2.5 mass concentration of residential buildings was 13.6-57.9 $\mu \mathrm{g} / \mathrm{m}^{3}$, and that of workplaces was $9.9-58.5 \mu \mathrm{g} / \mathrm{m}^{3}$. In addition, $\mathrm{He}$ et al.[8] showed that in the process of smoking, barbecue and frying, indoor PM2.5 concentration could be increased by 3 times, 30 times and 90 times of the background value, respectively. Smoking, cooking and resuscitation of particulate matter are determinants of indoor particulate matter concentration [9].

In Tibetan areas of western Sichuan, China, coal stove heating is the main way of heating, other heating methods include heating fan heating, floor radiant heating, electric radiant heating, etc. Different from other countries and cities, western Sichuan has good outdoor air quality and low PM2.5 concentration. However, due to the restriction of heating methods, the outdoor PM2.5 concentration near buildings will increase to a certain extent. In order to study the indoor air quality under different heating modes in western Sichuan, the indoor air quality of residential buildings, hotel buildings, office buildings and

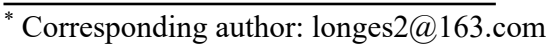


commercial buildings in Songpan County was measured.

\section{Experimental Setting}

\subsection{Measured building and heating mode}

The four building types measured in this paper correspond to four heating modes respectively, which are: heating by air heater in residential buildings, floor radiant heating by low-temperature hot water in hotel buildings, electric radiant heating in office buildings and coal stove heating in commercial buildings. The corresponding measured buildings are shown in Fig. 1-4.

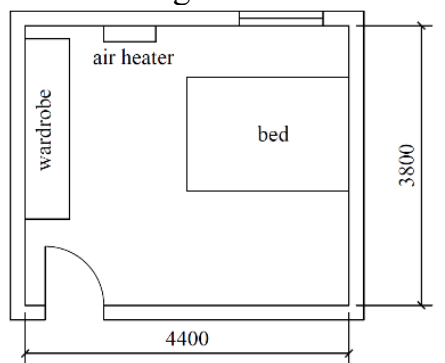

Fig. 1. Heating by air heater (residential building)

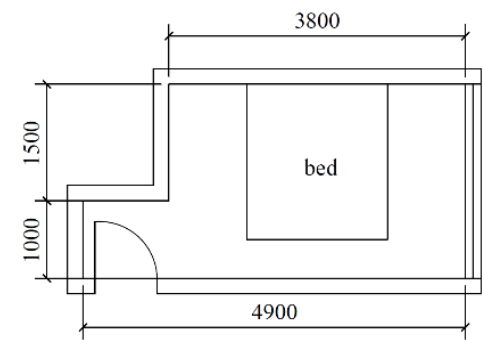

Fig. 2. Low-temperature Hot Water Floor Radiant Heating (Hotel Building)

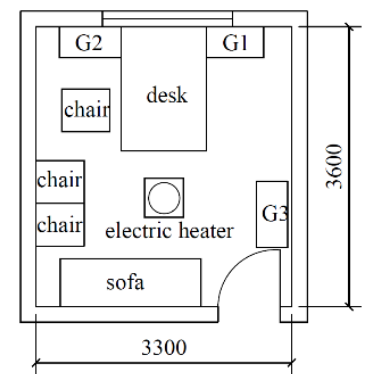

Fig. 3. Electric radiant heating (office building)

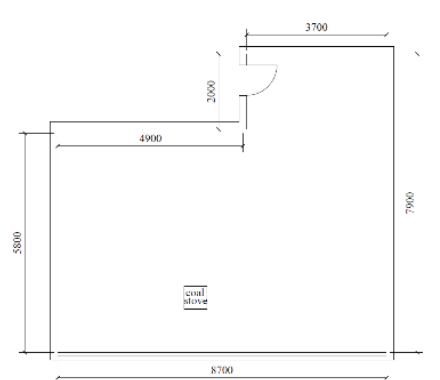

Fig. 4. Coal stove heating (commercial buildings)

\subsection{Testing Instruments}

The test parameters of this experiment are indoor and outdoor PM2.5 concentration, PM2.5 concentration is measured by the Air Castle PM2.5 detector, the measurement range is $0 \sim 999+\mu \mathrm{g} / \mathrm{m}^{3}$, the measurement accuracy is $\pm 1 \mu \mathrm{g} / \mathrm{m}^{3}$. A PM2.5 detector is placed outdoors and a PM2.5 detector is placed indoors in the central area.

\section{Results and discussion}

\subsection{PM2.5 concentration under heating by air heaters}

As can be seen from Figure 5, the overall indoor and outdoor air quality in Songpan County is good, and the outdoor PM2.5 concentration is below $100 \mu \mathrm{g} / \mathrm{m}^{3}$. The indoor PM2.5 concentration was below $70 \mu \mathrm{g} / \mathrm{m}^{3}$ and basically remained below $35 \mu \mathrm{g} / \mathrm{m}^{3}$. During 13:05 15:40, the indoor and outdoor PM2.5 concentration did not differ much; During 15:40 $\sim 17: 45$, the outdoor PM2.5 concentration was much higher than the indoor PM2.5 concentration. In the process of measurement, it was found that after 15:45, due to the shelter of the highland, the solar radiation entering the room gradually decreased, and the indoor temperature decreased. Therefore, the surrounding users chose to light coal stoves for heating, so the outdoor PM2.5 concentration rose. During the measurement period, the measured room was normally closed, and the indoor PM2.5 concentration gradually increased after 16:15, and then gradually decreased. The increasing and decreasing trend of indoor PM2.5 concentration is consistent with the changing trend of outdoor PM2.5 concentration, indicating that air leakage has a certain influence on indoor PM2.5 concentration.

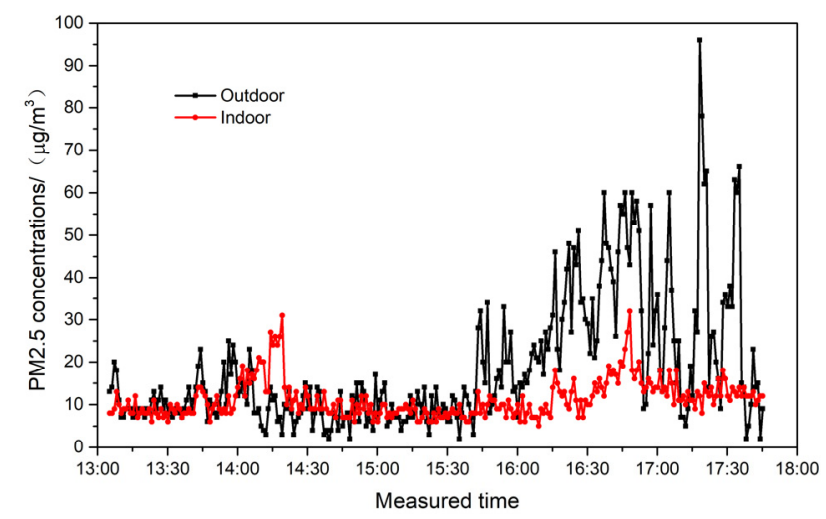

Fig. 5. Indoor and outdoor PM 2.5 concentrations under heating by air heaters

\subsection{PM2.5 concentration under low-temperature hot water floor radiant heating}

As can be seen from Figure 6, indoor air quality is better when this heating method is adopted, and indoor PM2.5 concentration is lower than $25 \mu \mathrm{g} / \mathrm{m}^{3}$. The outdoor PM2.5 concentration increased gradually, and the maximum value was $64 \mu \mathrm{g} / \mathrm{m}^{3}$. The indoor PM2.5 concentration decreased in the first half hour of measurement, and then increased with the increase of outdoor PM2.5 
concentration. The indoor PM2.5 concentration was the lowest of $3 \mu \mathrm{g} / \mathrm{m}^{3}$, and the highest of $24 \mu \mathrm{g} / \mathrm{m}^{3}$, indicating that air leakage had a certain effect on the indoor PM2.5 concentration.

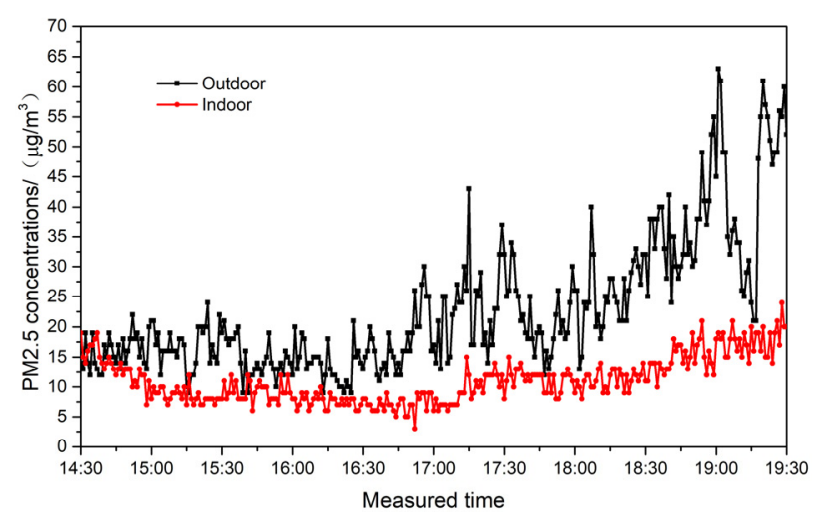

Fig. 6. Indoor and outdoor PM2.5 concentration under lowtemperature hot water floor radiant heating

\subsection{PM2.5 concentration under electric radiant heating}

As shown in Figure 7, the outdoor PM2.5 concentration fluctuated between 10 and $67 \mu \mathrm{g} / \mathrm{m}^{3}$ before $24: 00$. The reason was that the weather was relatively cold and residents lit coal stoves, which led to a high outdoor PM2.5. Correspondingly, the indoor PM2.5 concentration variation trend is basically consistent with it. After 24:00, the indoor and outdoor PM2.5 concentration does not differ much, and even the indoor PM2.5 concentration is slightly higher than the outdoor PM2.5 concentration. The reason is that the outdoor is relatively open and the houses are relatively sparse. When the surrounding users no longer burn coal stoves, the outdoor PM2.5 concentration can quickly spread and reduce. However, the indoor PM2.5 concentration reached a peak of $22 \mu \mathrm{g} / \mathrm{m}^{3}$ at $00: 08$. Later, due to the small difference between indoor and outdoor PM2.5 concentration, the indoor PM2.5 concentration tends to be stable. Indoor space is limited and has a certain airtight property, so it drops slowly.

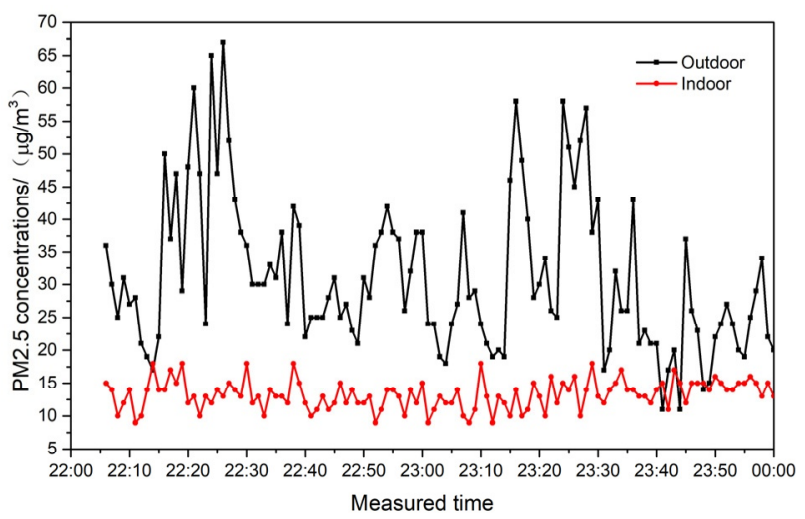

Fig. 7. Indoor and outdoor PM2.5 concentration under electric radiant heating

\subsection{PM2.5 concentration under coal stove heating}

Different from the above three heating methods, coal stove heating itself will produce a certain amount of PM2.5, and due to the characteristics of this building type, the increased value of PM2.5 caused by smoking behavior is higher. As can be seen from Figure 8, the outdoor PM2.5 concentration is below $200 \mu \mathrm{g} / \mathrm{m}^{3}$, and most of them are below 100 $\mu \mathrm{g} / \mathrm{m}^{3}$. During 11:27 12:19, there were only four people in the chess room and no one smoked. The coal stove was burning, so the initial concentration of PM2.5 in the room was low and the change was small. From 12:20 to 15:09, some people entered the chess room one after another and some guests began to smoke. During this period, the indoor PM2.5 concentration was high. After 16:10, all the guests left the chess and card room. At this time, the PM2.5 concentration began to decrease gradually and gradually stabilized at 19:00.

The variation of indoor PM2.5 shows a certain curve. At the beginning, when the number of smokers is large, PM2.5 increases rapidly, and when smoking is stopped, PM2.5 concentration decreases obviously. When the indoor PM2.5 concentration tends to saturation, its rise and fall are not as large as the initial range; When the release source of PM2.5 leaves the chess and card room, the indoor PM2.5 gradually decreases, and finally becomes stable and slightly higher than the initial value.

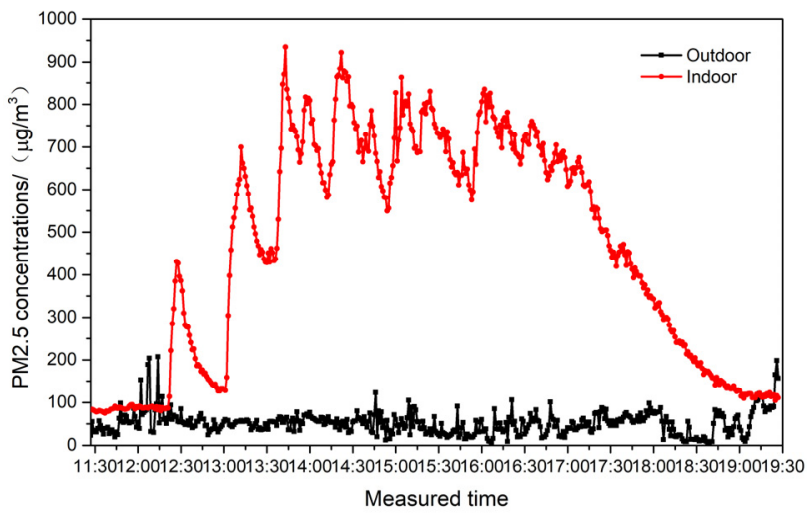

Fig. 8. Indoor and outdoor PM2.5 concentration under coal stove heating

\section{Conclusions}

By comparing the indoor PM2.5 concentration under the above four heating methods, the following conclusions can be drawn:

(1) For heating by air heaters, the reason for the increase of indoor PM2.5 is air leakage; The PM2.5 concentration changes greatly and significantly when the air heater is heating. The reason is that the indoor air disturbance will be caused when the air heater is heating, and the air disturbance will lead to the migration of indoor PM2.5.

(2) For low-temperature hot water floor radiant heating, the indoor PM2.5 concentration change is relatively stable, and the overall change trend is consistent with the outdoor PM2.5 concentration change trend.

(3) For electric radiant heating, the variation of indoor PM2.5 does not fluctuate much, and is less affected by the concentration of outdoor PM2.5, indicating that such buildings have good air tightness.

(4) For coal stove heating, the outdoor PM2.5 
concentration does not change much, but the indoor PM2.5 concentration changes greatly. At the beginning of the measurement, the burning of coal stoves was more intense and the outdoor PM2.5 concentration increased, but the indoor PM2.5 concentration did not change much at this time. Therefore, the influence of coal stove combustion on the indoor PM2.5 concentration was limited, and smoking behavior was the main reason for the high indoor PM2.5 concentration.

(5) The degree of influence of indoor activities on indoor particle concentration level depends on the source and characteristics of the house. Compared with the four heating methods, the three heating methods are relatively clean, including air heater heating, floor radiant heating and electric radiant heating. Coal stove heating is the main source of PM2.5 release. Among the three cleaner heating methods, the outdoor PM2.5 concentration is higher than the indoor PM2.5 concentration, while for coal stove heating, the indoor PM2.5 concentration is higher than the outdoor PM2.5 concentration, because the heating method itself will release a certain amount of PM2.5, in addition, its building form also leads to the indoor PM2.5 concentration is much higher than other building types.

(6) By comparing three relatively clean heating methods, it is obvious that the variation trend of indoor PM2.5 concentration is consistent with that of outdoor PM2.5 concentration. Therefore, air leakage is one of the main reasons for the increase of indoor PM2.5.

(7) When the disturbance of indoor air by heating method is small, the change of PM2.5 concentration is stable, such as electric radiation heating; However, when the indoor air is disturbed greatly by the heating mode, the PM2.5 concentration changes more violently.

Thus, air disturbance can affect the migration of PM2.5.

\section{Acknowledgements}

This work was supported by the National Natural Science Foundation of China [No. 52078314, No.51778382].

\section{References}

1. Wallace, L., 1996. Indoor particles: a review. Journal of the Air \&Waste Management Association 46, 98126.

2. Haller, L., Claiborn, C., Larson, T., Koenig, J., Norris, G., Edgar, R., 1999. Airborne particulate matter size distributions in an arid urban area. Journal of the Air and Waste Management Association 49, 161-168.

3. Jones, N.C., Thornton, C.A., Mark, D., Harrison, R.M., 2000. Indoor/outdoor relationships of particulate matter in domestic homes with roadside, urban and rural locations. Atmospheric Environment 34, 2603-2612.

4. Zhu, C., Cao, J., Tsai, C., Shen, Z., Ho, K., Liu, S., 2010. The indoor and outdoor carbonaceous pollution during winter and summer in rural areas of Shaanxi, China,. Aerosol and Air Quality Research 10, 550-558.

5. Cao, J.J., Lee, S.C., Chow, J.C., Cheng, Y., Ho1, K.F.,
Fung, K., Liu, S.X.,Watson J. G, 2005. Indoor/outdoor relationships for PM2.5 and associated carbonaceous pollutants at residential homes in Hong Kong e case study, Blackwell Munksgaard. Indoor Air 15, 197e204.

6. Greene, N.A., Morris, V.R., 2006. Assessment of public health risks associated with atmospheric exposure to PM2.5 inWashington, DC, USA. International Journal of Environmental Research and Public Health 3 (1), 86-97.

7. Chunram, N., Vinitketkumnuen, V., Deming, R.L., Chantara, S., 2007. Indoor and outdoor levels of PM2.5 from selected residential and workplace buildings in Chiang Mai. Chiang Mai Journal of Science 34 (2), 219-226.

8. He, C., Morawska, L., Hitchins, J., Gilbert, D., 2004. Contribution from indoor sources to particle number and mass concentrations in residential houses. Atmospheric Environment 38 (21), 3405e3415.

9. Mohammadyan, M., Ashmore, M., Shabankhani, B., 2008. Indoor PM2.5 concentrations in the office, café, and home. International Journal of Occupation Hygiene 2, 57-62. 